\title{
Pre-service Teachers' Perception of Teaching Future EFL Students: A Micro-ethnography Approach
}

\author{
Widya Ratna Kusumaningrum \\ Tidar University, Indonesia
}

\begin{abstract}
As an archipelagic state, teaching English in Indonesia is not easy to deal with. Its diverse sociocultural context causes the assumption that to teach English as a foreign language varies. This paper studies the pre-service students' perspective on how to teach future EFL learners in the Indonesian context. The participants of this study were 150 pre-service teachers aged 20-24 years old who had comprehended such TEFL concept in the 50-hour course. Using a micro-ethnography approach, this issue was investigated and observed for one year. It tried to understand the perception of pre-service teachers in terms of putting theories into practices. To portray this perception, this study used fieldwork, interview and questionnaire. The result showed that students had a similar perception, in which they included the Indonesian context in designing a lesson as well as acting out as classroom teachers. In the interaction process, they tried to engage students with Indonesian context rather than English context. Yet, it results into bad implication in which both pre-service teachers and their future students will not learn English in the proper context. As pre-service teachers, they should not teach in their comfort zone and start to learn to include English socio-cultural context when they teach English.
\end{abstract}

Index Terms - micro-ethnography, pre-service teacher, students' perception, socio-cultural context

\section{INTRODUCTION}

Prior to the professional development, most competent and experienced teachers have their educational initiative as pre-service teachers. They should have clear images of their future teaching (Chong, Low, \& Goh, 2011). As the initial steps, they need to embrace their teaching knowledge, skills, and abilities before field experiences. Seen as long-term investments and assets in an educational context, they hold the responsibility to form better generation. They have a greater task in which the current picture of education has been wrongly implemented and fossilized. The roots of failure in an educational setting are varied such as an educational system, teachers' status and motivation, examination pattern, teachers' preparation, method of teaching the availability of qualified teachers (Olurenfemi-Olabisi, 2013), inadequate exposure to teaching practice (Okubukola, 2005), the use of media (Okpala, 2006), and teaching strategies (Ebenezer, 2009), and teaching materials. These factors somehow weigh and burden these pre-service teachers as future teachers. How will they respond to this poor education quality and shift from these problems to potential solution and practice?

Another challenge is encountered in the context of teaching a foreign language in a diverse culture state as in Indonesia. As one of subject courses in the Indonesian curriculum, teaching English demands more than just teaching knowledge, skills, or abilities, but it involves a good understanding of Indonesia as a foreign language country in general, and as an archipelagic state in a specific way. Indonesia, itself, has over 17,000 islands spread out from Sabang to Merauke (Murphy, 2010). This condition leads Indonesia to have diverse socio-cultural contexts. The diverse sociocultural contexts may cause a cultural mismatch and conflict between teachers and students, particularly if teachers are from different ethnic group, which presumably has a different native culture and vernacular or local languages. It has been surveyed that as a state, Indonesia has more than 550 known local languages (Sneddon, 2003) with varied dialects. These countless dialects cause diverse patterns of communication during classroom activities.

The variation of perception may go beyond since the diverse socio-cultural context in Indonesia is driven not only from the ethnicity factor but also from a religious perspective. It is widely known that Indonesia respects the religious issues. It is a home for 6 major religions such as Muslim, Protestant, Catholic, Hindu, Buddhist, and Confucianism. Unlike in the western countries as in the US, in which the religion subject is apart from the school curriculum, in Indonesia religion course becomes compulsory subject from elementary to university level as has been constituted in the education policy and curriculum. Another issue is that the Indonesian educational policy allows the concept of religion-based school, both in the city and in the countryside. As the consequences, it affects the learning materials used in the classroom. This system drives teachers' need to selectively choose learning materials in consideration, it will not harm their beliefs. So, teaching English will be intrinsically challenging for teachers. Since this belief has been instituted in the system, some collaborative schoolteachers who supervise pre-service teachers tend to push these preservice teachers to be extra-careful in choosing materials. Back to the intertwined and bound-together concept of language and culture, pre-service teachers will limit their teaching materials and for those who are teaching at the 
religion-based school, they are able to help the students to acquire a deep level of English. To address this issue, I propose the research question below:

RQ 1. What are the shared beliefs, values, and attitude of the pre-service teachers on how to teach future EFL learners in Indonesian context?

\section{Methodology}

The present research studied the pre-service teachers' perspective on how to teach future EFL learners in Indonesia. The issue was studied by using a qualitative micro-ethnography approach. It portrayed and noted a deep understanding on how these pre-service teachers expressed their beliefs, values, and attitude through their action, verbal, and engage in practices.

To understand the perspective, I spend a year from February to December 2016 to interview, observe, question, and gather the information. This research was situated at a state university in Magelang, Indonesia. I had flexible access to verify the record of their shared thoughts and actions comprehensively.

Narrowly framed, the research focused on 150 male and female pre-service teachers aged 20-24 years old. These participants, who were involved in the study, had joined for the 50-hour Teaching English as Foreign Languages (TEFL) course in 2016. These participants were Javanese with varied dialects and diverse culture, such as standard Javanese of Kedu sub-dialect (Kebumen, Purworejo, Magelang, Temanggung), Semarangan sub-dialect (Semarang), Yogyakarta sub-dialect (Yogyakarta), and Surakarta sub-dialect (Surakarta, Solo, Boyolali, Sukoharjo, and Karanganyar), as well as Banyumasan Javanese of Banyumasan sub-dialect (Banyumas, Purbalingga, Cilacap, Banjarnegara, Purwokerto).

To see what is actually happening and collecting such information, this study involved fieldwork, questionnaire and interview. Fieldwork functioned to back-up information, which was not easily uncovered through an interview or questionnaire. I learned how these pre-service teachers thought and acted slowly. In doing the fieldwork, this study used emic approach. The approach allowed this study to get the data from the participants and construct their perspective directly. Later, it allowed me to construct this perspective based on the recorded stories. It was essential to note that the fieldwork recorded both initial and final processes. In the initial process, all of the participants developed the background schemata about their teaching concept and tried to synthesize and construct the acquired knowledge from books and classroom discussion into their teaching practice in the final phase. Their construction was then developed into a lesson design and performed individually in the final process. Each pre-service teacher acted out as the real classroom teachers based on their own lesson plan.

Another tool used to collect the data was a questionnaire. The questionnaire was an open-ended questionnaire, which let the participants to answer honestly. It focused on the causes of failure in an educational setting (Olurenfemi-Olabisi, 2013) such as current and future Indonesian education system, current and future students' characteristics, teachers' qualification, teaching methods, the language philosophy, and teaching materials.

To triangulate the data, this study also conducted unstructured open-ended interviews. The interview was done randomly to some participants to confirm the results of fieldwork and the questionnaire given. In the interview session, I filtered and controlled the information needed to support this study. Each interview was audiotaped and transcribed.

In analyzing the data, this study used the qualitative process of data analysis (Creswell, 2012). This data analysis required six steps such as (1) data collection or data preparation, (2) data organization, (3) data exploration or data codification, (4) use the data codification to have the general description and image, (5) Illustrate the findings through the narrative description, and (6) making the interpretation of the findings and drawing the personal reflection on the impact might be caused from the study. Through the whole process, it was expected that the study was able to document these pre-service teachers perception and behavior.

\section{FINDINGS AND DISCUSSIONS}

\section{The Perception of Teaching EFL Learners in Indonesia}

The universal belief, values, and attitudes of the participants, in this case, pre-service teachers on how to teach future EFL learners in the Indonesian context were reflected on these aspects mentioned earlier. In general, it shared some common understanding such as the education system, student's characteristics, teacher's qualification, teaching methods, language philosophy, and learning materials.

\section{The Shared Beliefs on the Indonesian Education System}

More than 120 participants or $80 \%$ agreed that the current Indonesian education system was rated relatively low or bad. This perception was predominantly caused by the curriculum implemented across the country. These participants learned how the government or ministry of education and culture, in this case, keep changing the curriculum system. One of the current confusing systems is that the ministry has two curriculums namely School-based Curriculum (Curriculum 2006) and Curriculum 2013. For the last 4 years, the Curriculum 2013 has been implemented in some piloting schools. These schoolteachers, then, encountered a big perplexity, in which they have to teach the senior students with the School-based Curriculum and freshmen with the Curriculum 2013. They are required to think about the proper materials to meet the standard or core competencies that should be acquired in these two different curricula. 
"Indonesia is not ready with the two curriculums implemented together. It deals with the teacher's qualification and administration workload. Based on my observation, both curriculums were not implemented correctly. I could see how the School-based Curriculum affected the implementation of Curriculum 2013, or vice versa." (student 3)

Further investigated, these pre-service teachers' reasoned that there were some causing factors of this low rate such as the government intervention (political intervention), aiming at the evaluation system (national examination), focusing on the low cognitive level, disregarding the students' characteristics and needs, and so forth.

"I think our current education system had big intervention from government. When we have new minister we have a new policy in our education system like curriculum, five school days, new criteria of national examination" (student 22)

"In my assumption, our education system needs to highlight the students' characteristics. It was not as simple as having great ideas and implementing them in our education system. But, our government should appreciate the diverse students' needs across the cultures. Our government should balance between adoption with the Indonesian condition. Like as my cousin said that (he is teaching in Papua now), it was hard to make the children here to keep up with the Jakartanese students. Our government should see the education system from the rural places as well." (student 7).

In this case, these perceptions on current education system lead to pessimism on the future education system. 52 participants showed their negative attitude to it. Approximately one-third presumed that changing the future Indonesian education system tends to be predictably similar with today's education system, or even worse. As they argued, it could be caused some problems such as the teacher's qualification and understanding the students' needs.

"It's not about disrespecting our future education, but if we do not change what we have now, our future education system can be easily predicted that it will be similar to today's system." (student 11)

Yet, two-thirds of pre-service teachers still showed their positive attitude toward the future. One of the causes is affected by today's education system.

"Although it is not going to be rapid change, personally I believe that our future education system will be developed than today. Our government will learn from the world education system and try to catch up it. Actually, it could be seen from the nowadays curriculum 2013, in which it shows the effort of our government to focus on higher cognitive level and scientific approach. If there is consistency from the government, I think our education system will be better in the future." (student 16)

For about ninety-eight participants who had the positive sight toward the future education development gave varied reasons, particularly dealing with better students' characteristics, teacher's commitment, and rapid technology development.

"There are some reasons that I could think of. As you know, the infants or kids now are familiar with technology than our generation who know technology when we were senior high students. It means that this generation, who will be my students, will be better in terms of knowledge and intellectual development. They have access and I believe it will be future teachers like us to be aware of this condition. I am a bit afraid of since they will be more active and have better critical thinking." (student 22)

Although they had the same perception about the current education system, but there is a big difference between pros and contras, most of these pre-service teachers shared the same positive attitude about the future of Indonesian education system.

\section{The Common Viewpoints on the Indonesian Student's Characteristics}

The big number of the pre-service teachers tried to criticize about the current students' characteristics. For about 40 percent, these participants agreed that most of today's students are lacking at points such as passive, dependent, teachercentered, lazy, and so forth.

"Talking about students in today's student characteristics is talking about us. I do realize that most of us tend to be passive in the class and wait for the materials from the teachers." (student 29)

"I think most students who live in today's era are lazy, passive and unconfident. When they have assignment such as writing, they only write a simple paragraph with simple notion." (student 34)

Some focused on the difference between students' characteristics across the nation, in which culture binds their life aspects.

"In my opinion, the students' characteristics in Indonesia are not merely affected by the common characteristics such as intelligence and manner. In general, people may think that students in Borneo, or Papua, may be categorized as less intelligent compared to those in Java Island. But, it's not totally true. I think they have minimum exposure to the new knowledge and they value their culture in their life."

In more detail, they think that the future student characteristics are better. Over than $55 \%$ of the students had a typical opinion that they are much better in any aspects.

"If we are asked about the current student characters and the future student characters, I think they are better than us. As the rapid technology development grows, they will be more independent, creative, and critical. They may understand the learning materials better than us even though they may have minimum guidance from teachers." (student 39)

However, some emphasize on the cultural side. As they argue, the future could be better, worse, or similar to today's characteristics, in which all depends on how much the future generation wants to change and compete with other young generations all over the world. 
"Talking about future students is similar to predicting their characters. But, we can just say they are better than us. Once again, they are born from our culture. I think we hold big responsibility. If we as future teachers do not teach something good, we are not going to be developed" (student 45)

From this viewpoint, it is logical to infer that these pre-service teachers share the same optimism. As they believe, the future students will be better and enhanced than the present generation.

\section{The Universal Perception of Teacher's Qualification}

Predominantly, most of the pre-service teachers agreed that teachers should have good qualification. However, there is a significant difference on how they interpreted the notion of qualified teachers. It is mere 50 percent of the participants agreed that competent teachers are those with wide knowledge and skills. As they reasoned, teachers are responsible to transfer their knowledge and make the students comprehend the materials well.

"A qualified teacher should be knowledgeable and skillful. They should understand about the materials they are teaching. With the knowledge they have, they can attract the students' interest." (student 50)

"As a good teacher, they should be able to achieve the proposed learning goals. How can students understand the materials if the teacher himself does not comprehend the material?" (student 53)

30 percent of these pre-service teachers said that an experienced teacher should possess class management skill such as organizing and controlling the class.

"One of the characteristics of a good teacher is that they can make the learning enjoyable. A good teacher should know how to build the atmosphere and organize class well." (student 58)

The rest of 20 percent or 30 participants emphasize on the teacher's attitude and performance when they are teaching their students. As they persuaded, the prominent reason is the moral degradation in comparison to the past generation.

"One of the qualification a teacher should own is good behavior. Teachers will be the figure of their students. Probably, there are some smart teachers, but the challenge we have in the future is how the students' attitude is better than today since parents give all the responsibility to shape their character on teachers." (student 62)

At this point, these pre-service teachers highlight that knowledge, classroom management and teacher's attitude were the foremost three characteristics that a teacher should have for now and future teaching.

\section{The General Assumption of Teaching Methods}

Prominently, these pre-service teachers had a similar thought that today's teaching methods tend to be more traditional. Over $67 \%$ or two-third of the participants had a similar perception that the implemented teaching methods emphasize on activating students' participation.

"I personally keep thinking the existing teaching methods are used to attract the passive students and make them more active. So, sometimes the methods used are not in line with the method." (student 69)

"As I know, active learning is the foremost method in Indonesia now. Most of the schoolteachers are encouraged to use any media to make students actively involved in the classroom process. Schoolteachers usually use any colorful media to attract them". (student 71)

Further explored, some stated that the implemented teaching methods are closely related to the students' characteristics such as age level, proficiency level, as well as cultural perspective.

"When we use a teaching method, we have to consider many things such as age whether young or adult learners, as well as proficiency such as beginner or advanced. However, there is an aspect which is always ignored i.e. culture. When the implemented method is close to the origin culture such as an adaptation from traditional games, it would be easier for the students to collaboratively work with the teacher in the classroom. (student 77)

As these pre-service teachers are asked about future teaching methods, more than $85 \%$ agreed that the methods will be based on technology. More specifically, the use of technology cause the methods to be developed and varied. As they assumed, the rapid development of technology challenges the future teachers to dig their new ideas on teaching method. Besides that, these teachers have to think beyond merely activating students' participation, but integrating knowledge, experience, and students' need of it.

"I think the future teachers are required to develop more modernized, creative and innovative teaching methods. I believe technology plays a significant role here. So, the future teachers will have different objectives, in which it is no longer on activating students, but how these methods incorporate other things such as knowledge, and experience, as well as in line with the globalization" (student 82)

\section{The Distributed View of Language Philosophy}

The concept of language used in the classroom - whether it is supposed to be Javanese-English or English in the context of British or American English - has been widely debated. In Indonesia, the language will be the unsolved problem for years. This study explicitly showed that 40 percent of these pre-service teachers indicated the same tenet which involves the use of mixing both English and Javanese, with varied reasons.

"For me, using code mixing of the two languages, i.e. English and Javanese is more personal issue. I do believe that the mixing languages help the students to understand learning materials, particularly if the materials have difficult vocabulary. I think using translation method is the proper way. So, the students will understand the materials well" (student 87)

"I think mixing two languages is part of maintaining and preserving our local culture. Besides that we help our student to understand the materials." (student 94) 
Another 35 percent of the participants supported the notion of using English either British or American context. As they debated, the use of British or American English will help the future students master the language and its social context and give them proper exposure.

"As the future teachers, I think the use of British or American English is a way better for the student's development rather Javanese and English. At first, they may face difficulty in understanding and make them passive, but I believe that by having proper exposure these students are getting better and they can compete with other students from different countries. (student 97)

However, there is 20 percent who are confused about their own language philosophy. These 30 participants partially agreed on the use of mixing language Javanese-English and British or American-English.

"I think it is a difficult question to answer. Ideally, the use of American or British English is suggested for the future classroom. However, it is hard to deliver the materials in a hundred percent English if the students will not understand what we are talking about. Furthermore, as I observed most of these pre-service teachers have English difficulty. How could they claim that they are going to speak either British or American English? I don't think so. (student 103)

\section{The Notion of Learning Materials}

It is questionable if the learning materials should orient to the local content or western content. In this study, the preservice teacher's mindsets on the used learning materials were relatively varied. The highest percentage was 50 percent with the preference of combination between local and western content.

"I think the best way to choose the materials is that both considering curriculum and integrating the western country. I give you an example, if we want to teach legend we could use Indonesian legend as the primary materials, and western legend as the secondary materials." (student 112)

However, around 24 participants disagreed with this notion. As they rationalized, the learning materials should be based on the implemented curriculum and understandable for the students.

"Using the learning materials in public school is totally different from the private or international school. Teachers should emphasize on the material as suggested by the government, and somehow it limits our creativity on choosing the learning materials" (student 118)

Another big percentage, with 50\% also opposed this notion and preferred to choose western-content materials.

"In the future, there is a big challenge for the teachers. If we keep using local content or a combination, we could not keep up with the world development. It could cause Indonesia to be left behind." (student 124)

\section{The Gap Between Perception and Practice}

The major purpose of this study was to investigate the shared beliefs, values, and attitude of the pre-service teachers on how to teach future EFL learners in the Indonesian context. In order to clearly see their internal beliefs, values, and attitudes, we have to see how these pre-service teachers use their perception in the classroom, how they prepare the materials, how they manage and conduct their class, as well as how they motivate the students. Thus, the gap between the external perception, i.e. what has been written on the questionnaire and attitude on the fieldwork observation could be deeply investigated through interviews.

As mentioned above, there are some indicators investigated such as the education system, student's characteristics, teacher's qualification, teaching methods, language philosophy, and learning materials.

For some indicators such as education system and student's characteristics, the mismatch between the perception and practice could not be seen clearly since it deals with the governmental issue and unpredictable students' attitude in the classroom. Yet, other indicators are observable.

For the teacher's qualification indicator, these pre-service teachers point out knowledge, classroom management, and teacher's attitude. However, there is a significant difference between the perception and its implementation. For about 80 percent of the students were not really knowledgeable, such as when the students ask about the language features, they had difficulty in explaining the materials. For the classroom management, they had difficulty in controlling the naughty students and tended to focus on the students in the front. For the attitude, many pre-service teachers still treat their students as peers, in this case it will be hard to be a good role model for them.

For the teaching method, the gap is that when they believe that a better future education system could be achieved through technology development. However, during the individual teaching practice, less than 40 percent who used technology in their teaching practice. Once it was confirmed, they totally do not remember their own commitment in having a better future education regardless of the implemented curriculum.

For the language philosophy, most pre-service teachers declared to use the Javanese-English for preserving culture as purpose. However, from the practice it was clear that they use Javanese-English because their English skills remained on the low level. For those who claimed to use British or American English, they still had difficulty in distinguishing both standard dialects.

Last but not least, for the learning materials, as they claimed should be balanced between local-content and western content materials, but almost 80 percent of the students went back to the local content rather than having both of them. Furthermore, they have difficulty in choosing the proper materials for certain age and proficiency level.

\section{CONCLUSION}


At some point, this study is able to portray the pre-service teachers' perceptions and investigate how these perceptions are weak when they were asked to put into practice. However, this study has a limitation dealing with the scale of the project. Although the participants are big enough, describing Indonesian context is still hard to do. These participants are Javanese with sub-dialect differences. It is expected in the next coming project that the participants are culturally varied, so the result will be better.

\section{REFERENCES}

[1] Murphy, A.M. (2010). US Rapprochement with Indonesia: From Problem State to Partner. Contemporary Southeast Asia, 32(3), 362-387.

[2] Chong, S., Low, C.E., Goh, K.C. (2011). Emerging Professional Teacher Identity of Pre-Service Teachers. Australian Journal of Teacher Education, 36(8), 50-64.

[3] Creswell, J.W. (2012). Educational Research: Planning, conducting, and evaluating quantitative and qualitative research $\left(4^{\text {th }}\right.$ edition). Boston, MA: Pearson.

[4] Ebenezer. O.M.K. (2009). Strategies, Teaching, and Learning in Modern Society. A multi-Disciplinary Journal, 7(3), 95-102.

[5] Okebukola, P. (2005). Quality Assurance in Teacher Education. A publication of the Committee of Deans of Education in Nigerian Universities.

[6] Okpala, A. (2006). Towards effect teaching of music in Nigerian schools. International Journal of Research in education, 3(1), 157-163.

[7] Olurenfemi-Olabisi, F.A. (2013). Students' Perception of Teachers' Factor in the Teaching and Learning of English Language in Nigerian Secondary Schools. Journal of Educational and Social Research, 3(3), 173-179.

[8] Sneddon, J. (2003). The Indonesian Language: Its history and role in modern society. Sydney, NSW:UNSW Press.

Widya Ratna Kusumaningrum is currently working at the Department of English Education, Tidar University. Her research interest is in English Language Teaching in relation to socio-cultural context. Email: kusumaningrum@untidar.ac.id 